\title{
RNA Granules Present Only in Extracellular Toxoplasma Gondii Increase Parasite Viability
}

\author{
Dario Lirussi ${ }^{\bowtie}$ and Mariana Matrajt ${ }^{\bowtie}$ \\ Department of Microbiology and Molecular Genetics, University of Vermont, Burlington, VT 05405, USA
}

Corresponding author: Mariana Matrajt, Department of Microbiology and Molecular Genetics. 95 Carrigan Drive. University of Vermont, Burlington, VT. 05405. Tel: 802656 3671; Fax: 802-656 8747; E-mail: mmatraj@@uvm.edu. Dario Lirussi, Given Medical Building C321. 89 Beaumont Avenue. University of Vermont. Burlington, VT 05405. Tel: 001802 656 1018. Fax: 001802656 3854. E-mail: dlirussi@uvm.edu.

(c) Ivyspring International Publisher. This is an open-access article distributed under the terms of the Creative Commons License (http://creativecommons.org/ licenses/by-nc-nd/3.0/). Reproduction is permitted for personal, noncommercial use, provided that the article is in whole, unmodified, and properly cited.

Received: 2011.03.31; Accepted: 2011.07.26; Published: 2011.08.07

\begin{abstract}
Toxoplasma gondii is an obligate intracellular parasite. When searching for a new cell to invade, the parasites have to confront the stress of being exposed to the extracellular environment. The mechanisms by which $T$. gondii survives outside the host cells are poorly understood. In this work we show that extracellular parasites form mRNA aggregates with characteristics of stress granules. Intracellular tachyzoites or bradyzoites do not form mRNA granules. We tested different stimuli that trigger granule formation in vitro and discovered that a buffer that mimics the host cell cytosol ionic composition (high potassium) strongly induces granule formation, suggesting that the granules arise when the parasites come in contact with the host cell cytosol during egress. We examined the importance of granule formation for parasite viability and show that the parasite populations that are able to form granules have a growth advantage, increased invasion, and decreased apoptosis in the extracellular environment. Overall, granule formation improves the fitness of extracellular parasites and increases the efficiency of the lytic cycle.
\end{abstract}

Key words: RNA FISH, T gondii, stress granules, extracellularity, parasite fitness.

\section{Introduction}

The apicomplexan parasite Toxoplasma gondii is the causative agent of toxoplasmosis, an infection that is asymptomatic in healthy individuals but can be fatal in developing embryos and immunocompromised patients. The asymptomatic chronic phase is characterized by the presence of cysts containing slowly dividing parasites known as bradyzoites. The acute illness consists of rapidly dividing parasites known as tachyzoites. In the acute phase, the intracellular parasites egress (exit) breaking the host cell to reinvade a new one (lytic cycle). When searching for a new host cell to reinvade, the parasites are under the stress of the extracellular environment. When eukaryotic cells confront environmental stress they either initiate apoptosis or activate defense mechanisms such as the assembly of stress granules [1]. In higher eukaryotes, mRNA granules are typically divided in stress granules (SG) and processing bodies (PB), differing mainly by the presence of poly-A tails associated with Poly-A Binding Protein (PABP) in the transcripts. PB lack these two components [2]. The formation of SG has been linked to mRNA storage $[3 ; 4$; 5]. In this storage model, the cytosol is virtually depleted from existing templates which are recruited into the granules, allowing new actively transcribed mRNA to become translated, without competing with older templates for the translation machinery [3]. This allows the cell to respond rapidly to stressing conditions.

SG are conserved throughout evolution [1], and they are present in protozoan parasites. For instance, recent studies show the presence of mRNA granules 
in trypanosomes in some extracellular stages [6]. Malaria parasites, which are Toxoplasma relatives, display mRNA granules in sporozoites (extracellular stage in the mosquito)[5].

In this study, we show for the first time, the existence of stress granule like mRNA aggregates in $T$. gondii. We demonstrate the exclusive presence of these granules in extracellular invasive parasites, and we relate granule formation to dramatic changes in the ionic concentration occurring during egress. Finally, we show the biological relevance of the granules for extracellular survival, invasion and growth.

\section{Materials and Methods}

\section{T gondii strains}

Human foreskin fibroblasts (HFF) cells were used to maintain different $T$ gondii strains: $R H$ strain, Pru strain, and FLAG-TgRACK1 transgenic parasites.

\section{Buffers}

High [K+] buffer (pH 7.2): $142 \mathrm{mM} \mathrm{KCl}, 5 \mathrm{mM}$ $\mathrm{NaCl}, 2 \mathrm{mM}$ EGTA, $5 \mathrm{mM} \mathrm{MgCl} 2,25 \mathrm{mM}$ Hepes-KOH, $1 \mathrm{mg} / \mathrm{ml}$ BSA. Also used without EGTA.

High [Na+] buffer (pH 7.2): $120 \mathrm{mM} \mathrm{NaCl}, 1 \mathrm{mM}$ $\mathrm{CaCl} 2,5 \mathrm{mM} \mathrm{MgCl} 2,25 \mathrm{mM}$ Hepes-NaOH, $1 \mathrm{mg} / \mathrm{ml}$ BSA. Both buffers made according to [7].

Maleic acid buffer (pH 7.5): $0.1 \mathrm{M}$ maleic acid, $0.15 \mathrm{M} \mathrm{NaCl}[8]$.

\section{RNA FISH}

Freshly lysed parasites, released by scraping the monolayer in the presence of high $[\mathrm{K}+]$ or high $[\mathrm{Na}+]$ buffer, high $[\mathrm{K}+]$ without EGTA, and paraformaldehyde $4 \%$ in DEPC PBS (intracellular parasites), were incubated for one hour in high $[\mathrm{Na}+]$ buffer alone, or salubrinal $5 \mu \mathrm{M}$ (Enzo Life Sciences), or arsenite 10 $\mu \mathrm{M}$, or both salubrinal and arsenite. Alternatively, parasites were incubated in high $[\mathrm{K}+]$ for one hour when released in this buffer. After buffer incubation, the parasites were centrifuged, washed $10 \mathrm{~min}$ in 25 $\mathrm{mM} \mathrm{NH}_{4} \mathrm{Cl}$ and smeared on RNAse free slides. Slides with fixed dried parasites where framed using in situ frames (Thermo). The rest of the protocol was done according Thompson[8]. Briefly, framed slides were washed three times for 5 minutes with 2X SSPE buffer, then incubated or not for $7 \mathrm{~min}$ at room temperature (RT) with HCL $0.1 \mathrm{~N}$. After 3 washes with SSPE 2X, we included the following modifications: $10 \mathrm{U} / \mathrm{ml}$ of RNAsin (Promega), or alternatively, 2mM Vanadyl Ribonucleoside (NEB) in SSPE buffer and proteinase $\mathrm{K}$ (Fisher) adjusted to $0.1 \mu \mathrm{g} / \mathrm{ml}$. The hybridization solution contained $1 \mathrm{ng} / \mathrm{ml}$ of Cy5-oligo-dT (50mer from GeneLink), prepared with $0.5 \mathrm{mg} / \mathrm{ml}$ yeast
tRNA. The hybridizations were carried out overnight at $50^{\circ} \mathrm{C}$. Washes after hybridization were done according to Thompson [8]. A final wash in maleic acid buffer for $10 \mathrm{~min}$ was done followed by DAPI staining. Slides were mounted in Fluoromount (SouthernBiotech).

\section{Immunofluorescence assays (IFA)}

Parasites were fixed in paraformaldehyde $4 \%$ in DEPC PBS, permeabilized with $0.25 \%$ Triton-X-100 in PBS for 10 min or mock permeabilized and blocked with 1X PBS 1-2\% BSA for $30 \mathrm{~min}$. We used the following primary antibodies $(\mathrm{Ab})$ : human 14-3-3 (Epitomics) and PABP (SCB) with $92 \%$ and $88 \%$ sequence identity with $T$ gondii respectively; Anti-HA (Roche), anti-FLAG M2 ${ }^{\circledR}$ (Stratagene). Primary Abs were incubated for one hour. Secondary Abs conjugated with Alexa Fluor 350, 488, and 594 (Molecular Probes), were incubated for $30 \mathrm{~min}$. When FISH was performed after IFA, all solutions used were DEPC treated and samples were fixed again after the IFA.

\section{Plaque assays}

Parasites incubated for $1 \mathrm{~h}$ in high $[\mathrm{K}+]$ or high $[\mathrm{Na}+]$ were incubated or not in high $[\mathrm{Na}+]$ with $70 \mu \mathrm{M}$ of PDTC (Sigma) for $2 \mathrm{hrs}$ at $37^{\circ} \mathrm{C}$. Parasites where diluted at $130 / \mathrm{cm}^{2}$ and seeded on 24 well plates or T25 flasks. After 7 days, the monolayers were fixed with ethanol for $5 \mathrm{~min}$ and stained with crystal violet for $5 \mathrm{~min}(100 \mathrm{mg} / \mathrm{ml}$ in $\mathrm{EtOH}, 1 \%$ ammonium oxalate). Plates or flasks were rinsed with PBS, dried and the number of plaques was counted (PDTC treatment, 3 T25 flasks/treatment), or the lysis area was measured ( 24 well plates, 6 wells/treatment).

\section{Parasite replication}

Parasites incubated for $8 \mathrm{~min}$ in high $[\mathrm{K}+]$ or high $[\mathrm{Na}+]$ followed by an incubation in high $[\mathrm{Na}+]$ for $1 \mathrm{~h}$ were allowed to invade HFF cell monolayers for $1 \mathrm{~h}$ at $37^{\circ} \mathrm{C}$, and then washed three times with PBS. These assays were done in triplicate. Parasites per vacuole were counted $24 \mathrm{hrs}$ post invasion, and at least $\sim 200$ vacuoles were counted on three different slides.

\section{TUNEL assay}

Parasites pre-incubated in high $\left[\mathrm{Na}^{+}\right]$or high $[\mathrm{K}+]$ were incubated for $4 \mathrm{hrs}$ in high $[\mathrm{Na}+]$, then fixed and processed according to manufacturer instructions for In Situ Cell Death Detection Kit (Roche). Fluorescein incorporated signal was counterstained with DAPI. Data acquired from 2 different experiments, 4 samples each. An average of 50 parasites per sample were counted randomly. 


\section{Invasion assay}

A red/green invasion assay was carried out as described by Huynh[9]. Fifty fields/sample were counted at $600 \mathrm{X}$ magnification in triplicate.

\section{Imaging}

A Leica DMIRE2 fluorescence microscope (Leica Microsystems) coupled to an Orca II (Hamamatsu) camera was used. Images were processed and measured (granule size, 3D profile and plaque areas) using Improvision Openlab 4.0.2 software (Improvision-Perkin Elmer) and assembled in Adobe Photoshop CS 8.0.

\section{Statistics}

T-tests were performed and differences considered significant when $\mathrm{p}<0.05$.

\section{Results}

We identified Poly-A(+) mRNA granules in $T$ gondii parasites by RNA fluorescence in situ hybridization (RNA FISH) with oligo-dT conjugated to Cy5. We observed a homogeneous cytoplasmatic staining in intracellular tachyzoites or intracellular bradyzoites. In contrast, after egress from the host cell, extracellular parasites (both tachyzoites and bradyzoites) display a granulated pattern. The presence of mRNA granules is not strain restricted since both RH (type I) and Pru (type II) strains display granules as extracellular parasites (Fig 1A).

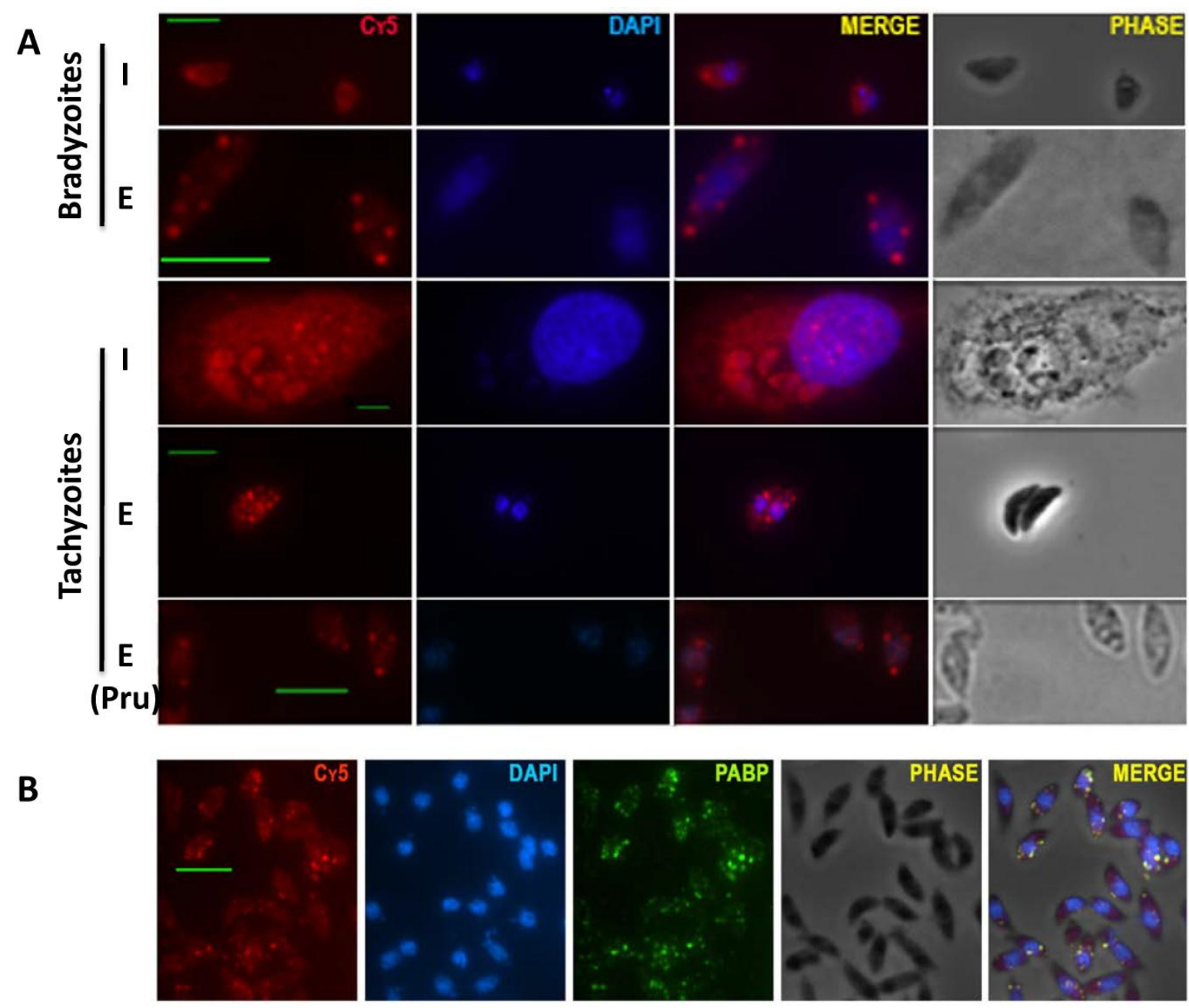

Figure 1. The presence of mRNA aggregates with characteristics of stress granules (SG) is restricted to extracellular parasites. A) RNA FISH carried out with parasites grown under bradyzoite or tachyzoite conditions. (I): intracellular parasites; $(E)$ : extracellular parasites. All experiments were done with type I RH strain, except for the one indicated with (Pru) that corresponds to type II Pru strain. (Cy5): poly(A) RNA detected with oligo-dT - Cy5. DAPI staining (blue). B) Immunofluorescence assay (IFA) carried out with antibodies against Poly A Binding Protein (PABP, green), followed by RNA FISH with oligo-dT conjugated to Cy5 (Cy5, red) and DAPI staining (blue). Scale bar: $5 \mu \mathrm{m}$. 
Cytosolic mRNA granules are traditionally divided into stress granules (SG) and processing bodies (PB). SG are mainly related to functions of sorting and storage of non-translating messenger RNA during stress, and PB are associated to mRNA degradation and contain decapping and deadenylase complexes [10; 11]. To examine if these granules have characteristics of stress granules, extracellular parasites were tested for the presence of poly A binding protein (PABP) which is absent in processing bodies. PABP co-localizes with the granules suggesting these are SG (Fig. 1B).

Recently, it was suggested that T. gondii argonaute (TgAGO) localizes to cytosolic granules of unidentified nature, and also it was shown that TgAGO interacts with the protein 14-3-3 [12]. In higher eukaryotes, 14-3-3 proteins are involved in the sorting of some members of the argonaute family among distinct classes of RNA granules [13]. Argonaute members have been consistently associated with degradative pathways related to PB $[14 ; 15 ; 16]$.We examined whether TgAGO and/or 14-3-3 co-localize with the granules shown in Fig. 1. None of these proteins co-localize with the mRNA granules shown in the present study (Supplementary Material: Fig. S1), suggesting that these are not $\mathrm{PB}$.

Tachyzoites live and replicate within an intracellular parasitophorous vacuole (PV). When the tachyzoites naturally egress from the host cells, the PV membrane breaks and the parasites are first exposed to the cytosol of the host cell, followed by host plasma membrane rupture which exposes the parasites to the extracellular milieu $[17 ; 18 ; 19]$. We therefore used two different buffers to mimic the host cell cytosol ionic composition (high $[\mathrm{K}+]$ ), and the extracellular ionic composition (high $[\mathrm{Na}+]$ ).

To examine granule formation, the parasites were forced to leave the host cells in either the high $[\mathrm{K}+]$ buffer or high $[\mathrm{Na}+]$ buffer. Interestingly, the parasites formed granules very rapidly in the high $[\mathrm{K}+]$ buffer (3 minutes). In contrast, when the parasites were released from the host cells in the high $[\mathrm{Na}+]$ buffer, they did not develop granules after 24 minutes of incubation (Fig. 2A). These results suggest that the granules arise promptly when the parasites come into contact with the host cell cytosol.

To test what conditions trigger granule formation in T. gondii, we tested other possible inducers of granule formation, such as arsenite and salubrinal. Salubrinal is an inhibitor of eIF2 $\alpha-P$ dephosphorylation and it may have an indirect effect on SG formation through protein synthesis inhibition [20]. When all treatments were compared, we observed that each condition generates granules with different characteristics and different abundance in the parasite population (Fig. 2B-E). We found significant differences $(p<0.05)$ in the average granule size and in the number of parasites with granules. High $[\mathrm{K}+]$ generates the biggest size granules and they are present in $91.5 \%$ of the parasites (Fig. 2D-E). In arsenite and salubrinal $44.5 \%$ and $62.8 \%$ of the parasites contain granules respectively, and only $20 \%$ of the parasites form granules when incubated in high $[\mathrm{Na}+]$ for 1 hour (Fig. 2E).

In order to test the importance of granule formation for parasite viability, we performed growth assays, invasion assays and apoptosis assays. To directly assess whether the population that contains many parasites with granules has increased fitness relative to the population with few parasites forming granules, we performed these assays in the high $[\mathrm{K}+]$ and high $[\mathrm{Na}+]$ buffers since these two conditions proved to be the most extreme ( $90 \%$ vs. $20 \%$ parasites with granules, Fig. 2).

To examine parasite growth, we performed plaque assays and replication rate assays (Fig. $3 \mathrm{~A}-\mathrm{C}$ ). We observed that the plaque size and plaque number is significantly bigger in the parasite population that contains granules or pretreated in high $[\mathrm{K}+]$ (Fig. $3 \mathrm{~A}$ and data not shown). Pyrrolidine dithiocarbamate (PDTC) is a well-known oxidant that induces apoptosis in a number of cell types and it selectively kills extracellular tachyzoites at very low concentrations [21]. We also performed plaque assays with parasites treated with $70 \mu \mathrm{M}$ PDTC during 2 hours after 1 hour under high $[\mathrm{Na}+]$ or $[\mathrm{K}+]$. In these harsh conditions, the population with a higher frequency of parasites forming granules was able to generate a larger number of plaques (Fig. 3B). Taken together, these results show a significant difference in growth with or without granules and strongly suggest that the parasites that form granules are more viable. In order to further explore if intracellular tachyzoites (which normally do not contain granules) and extracellular tachyzoites handle oxidative stress in similar ways, we treated the parasites with hydrogen peroxide and measured the glutathione levels. We observed an increase in the glutathione levels only in the intracellular tachyzoites, suggesting that extracellular tachyzoites do not depend on a classical anti-oxidant glutathione response to handle oxidative stress (Supplementary Material: Fig. S2).

To test if having granules during the extracellular phase of the lytic cycle gives a growth advantage to the parasites after they reinvade new host cells, we pretreated the parasites in high $[\mathrm{K}+]$ or high $\left[\mathrm{Na}^{+}\right]$ and then allowed them to invade a new host cell monolayer. We observed that the number of parasites 
per vacuole, 24 hours post invasion, is significantly higher in the parasites that formed granules ( 16 vs. $\sim 8$ parasites per vacuole) (Fig. 3C). These results suggest that the granules confer a growth advantage to the parasites.
To examine parasite invasion, we carried out an established red/green invasion assay with parasites pretreated in high $[\mathrm{K}+]$ or high $[\mathrm{Na}+]$. The parasites with granules showed a significant increase in their ability to penetrate the host cells (Fig. 3D).

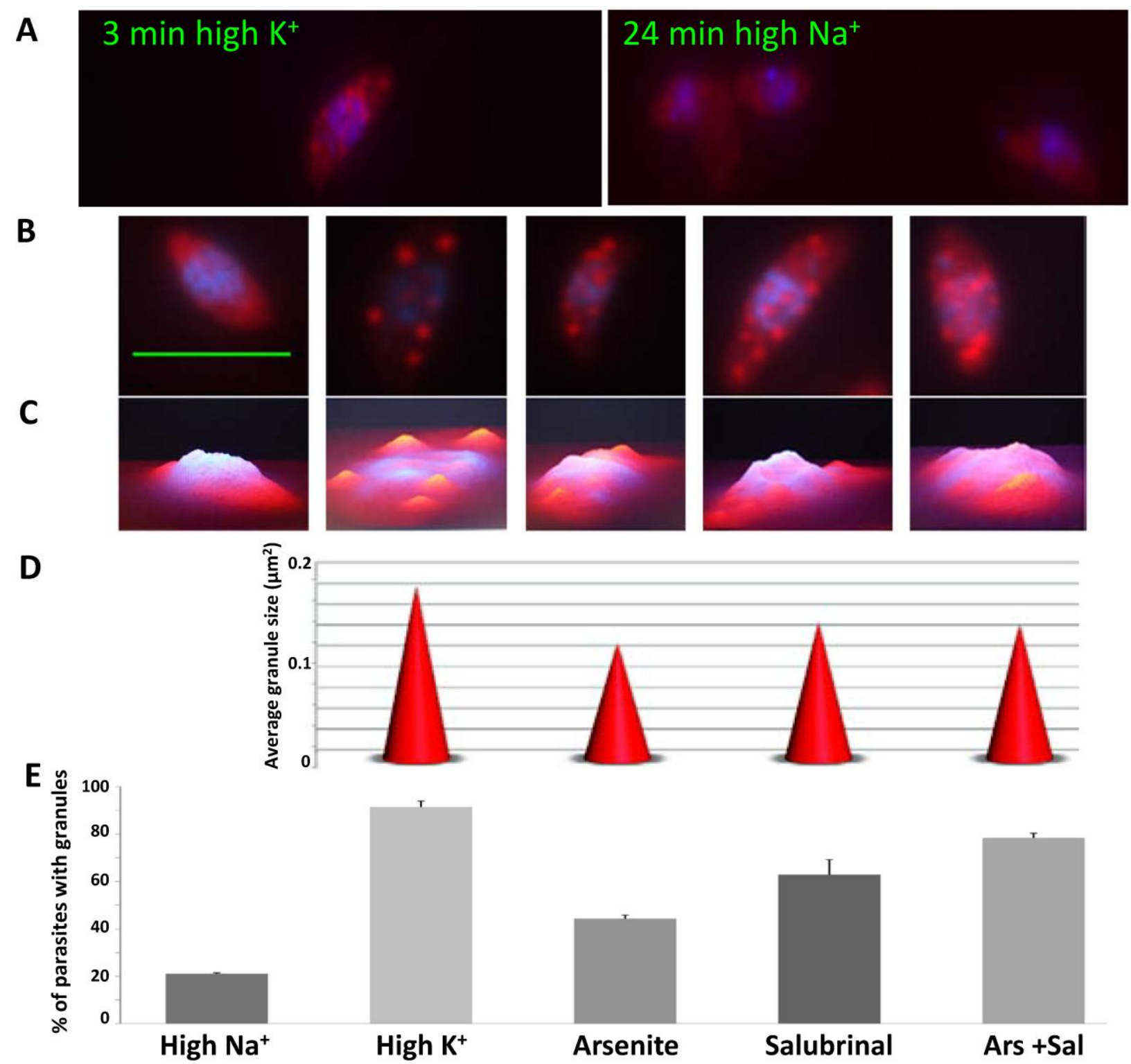

Figure 2. Different mRNA granule inducing conditions generate granules with different characteristics. A) Time course of granule formation. Infected host cell monolayers were scraped in either high $\mathrm{K}+$ buffer or high $\mathrm{Na}+$ buffer, and incubated for different times. Parasites were fixed every 3 minutes ( 0 to $24 \mathrm{~min}$ ) and RNA FISH was carried out against total polyadenylated RNA (Cy5, red) followed by DAPI staining (blue). Representative images of times 3 and 24 min in high $\mathrm{K}+$ and high $\mathrm{Na}+$ respectively. B) Representative images of granules formed in different inducing conditions: high $\mathrm{Na}+$, high $\mathrm{K}+$, Arsenite, Salubrinal and Arsenite + Salubrinal (from left to right). C) 3D profile of images shown in B. D) Granule size in different inducing conditions (shown in B). We show the average granule size of 100 parasites. All differences are significant (t tests with $\mathrm{p}<0.05$ ), except for the comparison Salubrinal with Arsenite + Salubrinal which is not significant. E) Percentage of parasites that contain granules, in different inducing conditions. We counted 200 parasites in triplicate experiments. All differences are significant ( $t$ tests with $p<0.05$ ), except for the comparison Arsenite with Salubrinal and the comparison Salubrinal with Arsenite + Salubrinal. Scale bar $5 \mu \mathrm{m}$. 
A

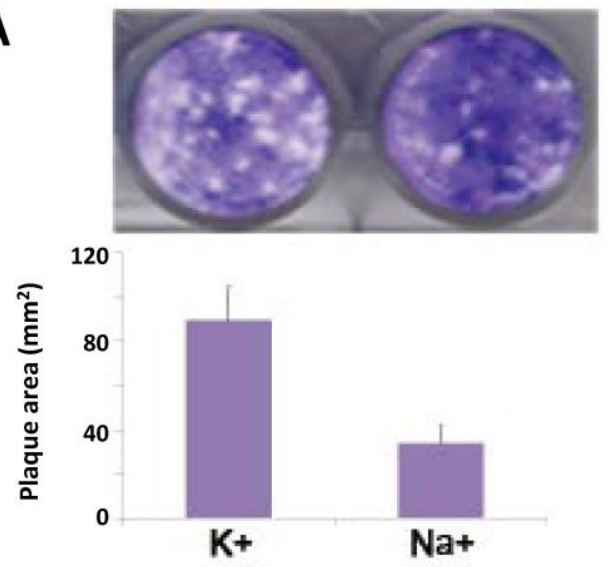

B

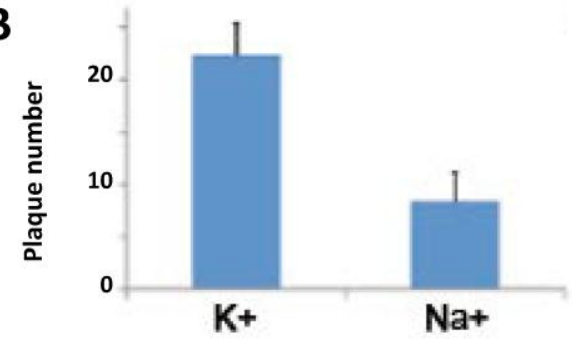

D

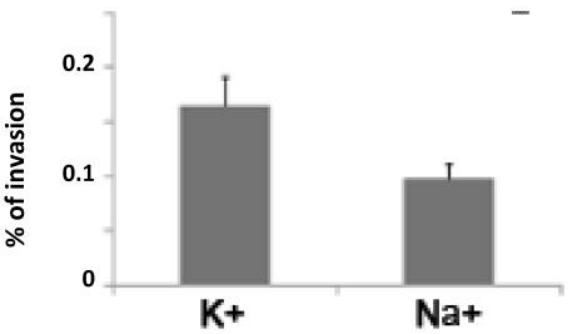

C

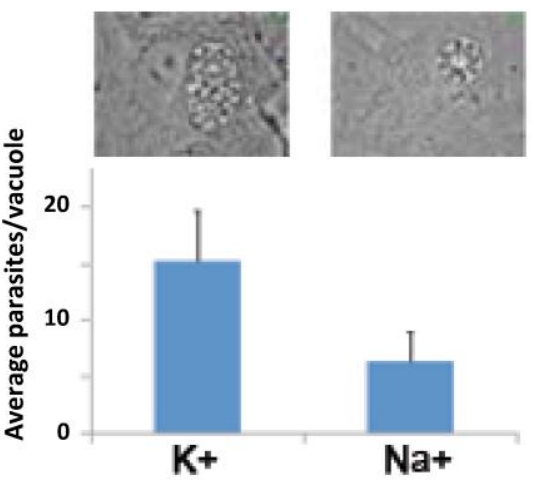

E

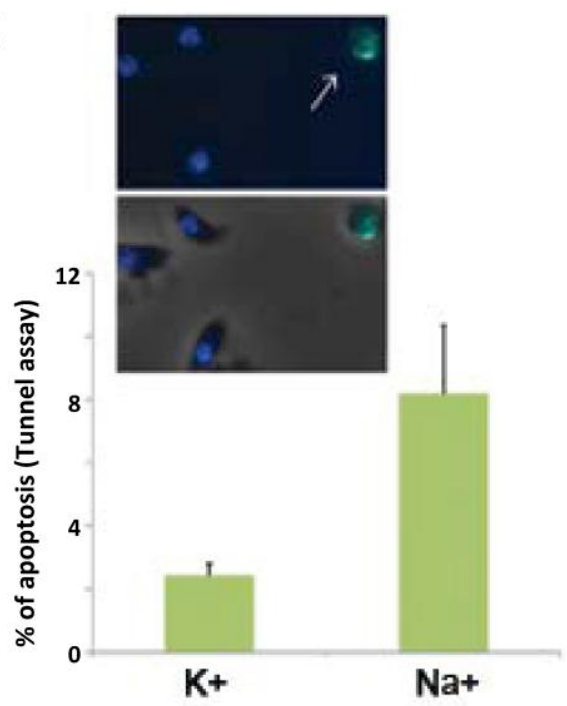

Figure 3. RNA granules increase parasite fitness. A) The plaque size (area in $\mathrm{mm}^{2}$ ) was measured in quadruplicate experiments. A representative picture of plaques obtained in high $\mathrm{K}+$ or high $\mathrm{Na}+$ is shown (top). B) Parasites were incubated in high $\mathrm{K}+$ or high $\mathrm{Na}+$ followed by PDTC $(70 \mu \mathrm{M})$ for $2 \mathrm{hrs}$, and the number of plaques was counted in triplicate experiments. C) Parasites pre-treated for 8 minutes in high $\mathrm{K}+$ or not (high $\mathrm{Na}+$ ) were allowed to invade a new host cell monolayer and the number of parasites per vacuole was counted ( $24 \mathrm{hrs}$ post-invasion) in triplicate experiments. A representative image is shown (top). D) Red/green invasion assay. Parasites were incubated as in C, and allowed to invade for 4 minutes. E) Apoptosis measured by TUNEL assay. A representative image is shown (top). The arrow indicates a TUNEL positive rounded shaped parasite. All differences between treatments in $A-E$ are significant ( $t$ tests with $p<0.05$ ).

In higher eukaryotes, it was demonstrated that SG formation inhibits apoptosis induced by certain types of stress [22]. To study if the apoptosis of extracellular parasites is affected by granule formation, we performed a TUNEL assay. The percentage of parasites positive for nuclear DNA cleavage, visualized by TUNEL, was significantly lower in the parasites that contain granules (Fig. 3E). This result suggests that granule formation helps to prevent apoptosis in the extracellular environment.

Taken together, these results (Fig. 3A-E) indicate that granule formation increases the fitness of extracellular parasites.

\section{Discussion}

This study shows that extracellular $T$ gondii rapidly forms mRNA aggregates with characteristics of stress granules (SG). These SG improve the fitness of extracellular parasites and increase the efficiency of the lytic cycle. Intracellular tachyzoites and bradyzoites do not form mRNA granules. In a recent genome-wide study, we have shown that extracellular parasites, intracellular tachyzoites and bradyzoites have significantly different expression profiles, which leaded us to propose a novel extracellular state within the T. gondii asexual cycle [23]. This work further 
suggests that extracellular parasites have a distinct cell physiology.

Considering that the formation of granules increases the parasite fitness, one plausible explanation is that the mRNA granules concentrate several transcripts that are important for intracellular survival (not required on extracellularity) allowing for the rapid translation of newly synthesized mRNA. This would permit the storage of "intracellular" transcripts without competing with the "extracellular" ones for the translation machinery. Upon invasion, the granules dissolve and the stored mRNA is released allowing for a rapid intracellular establishment, which could explain why the parasites that formed granules replicate faster after invasion. Conversely, if the granules are not formed after parasite egress, the "intracellular" and "extracellular" transcripts could compete for the translation machinery resulting in a diminished adaptation to the extracellular environment, which could explain the increased apoptosis and reduced invasion. This model suggests that some of the transcripts synthesized during a particular phase of the lytic cycle are stored in the granules to be used (translated) in the next cycle. This model is similar to what was demonstrated for another closely related apicomplexan, Plasmodium berghei [5].

In higher eukaryotes, the protein Receptor for Activated C Kinase 1 (RACK1) is sequestered into SG which prevents the activation of MAPK pathways that normally lead to apoptosis [22]. The T. gondii RACK1 protein has been cloned and characterized. It localizes to the cytoplasm and the perinuclear and nuclear region in tachyzoites [24]. T. gondii produces a large amount of RACK1 and it is not sequestered into the granules (Supplementary Material: Fig. S1C), suggesting that sequestration of RACK1 is not involved in the inhibition of apoptosis. However, like in higher eukaryotes, we found that SG formation inhibits apoptosis in T. gondii (Fig. 3E).

In some cases in higher eukaryotes, it was shown that SG formation occurs upon certain stress types that trigger the phosphorylation of the translation initiation factor elF $2 \alpha$, resulting in global translational silencing [1]. In T. gondii, the phosphorylation of this translation factor, $\operatorname{TglF} 2 \alpha$, also results in translational silencing, and Salubrinal functions as an inhibitor of TgIF2 $\alpha$ dephosphorylation [20]. Therefore, it is very likely that the Salubrinal treatment (Fig. 2 B-E) induces granule formation in $T$. gondii with a similar mechanism as the one described for the eukaryotic elF2 $\alpha$ [1]. Interestingly, a mutant of TgIF $2 \alpha$ that cannot be phosphorylated, is impaired in its ability to survive in the extracellular environment [25], which is consistent with our results that show SG improve the fitness of extracellular parasites. On the other hand, it was reported that high $[\mathrm{K}+]$ increases protein synthesis in extracellular parasites [26]. This report, together with our results that show that the granule size and abundance is different in high $[\mathrm{K}+]$ and Salubrinal (Fig. 2 B-E), strongly suggests that the mechanism of granule formation is different in these two conditions.

Schwab et al., suggested that the parasitophorous vacuole membrane acts as a "molecular sieve" and therefore, it was postulated that the ionic composition between the parasitophorous vacuole lumen and the host cell cytosol is homogeneous [27]. However, this assumption is not supported by recent reports that show that there are active ionic pumps on the parasitophorous vacuole [28]; there is an increase of potassium and the decrease of cytosolic sodium in the host cell during $T$ gondii infection [29]; the recruitment of host endoplasmic reticulum (ER) to the parasitophorous vacuole and the demonstrated interconnectivity with the host ER [30]. In vivo, host cell parasite exit occurs by "externally triggered egress" (ETE), and this mode of egress doesn't involve rupture of the host cell membrane before the PV disintegration [19]. The first event in ETE is the escape of the parasites from the PV while the host cell maintains an intact plasma membrane [19]. The parasite journey through the host's cytosol can last 1 to 10 minutes upon parasitophorous vacuole rupture[17], which is enough time under cytosolic high $[\mathrm{K}+]$ to trigger mRNA granule formation (Fig. 2A). Therefore, we propose that the high $[\mathrm{K}+]$ in the host cell cytosol is the natural stimulus for stress granule formation in extracellular $T$ gondii parasites.

T. gondii has adapted to live and replicate within animal cells and it has to survive the stressing conditions of the extracellular environment when searching for a host cell to invade. Very little is known about the mechanisms by which the parasites endure outside the host cells. In this work, we show that the parasite populations that are able to form granules have a growth advantage, increased invasion, and decreased apoptosis in the extracellular milieu. Thus, we propose that $T$. gondii exploits a stress response conserved in eukaryotic cells to survive in the extracellular environment.

\section{Supplementary Material}

Figure S1: Immunofluorescence assay followed by RNA FISH (Poly (A)+ mRNA: Cy5). Figure S2: Changes in reduced glutathione (GSH) measured upon oxidative induction with $\mathrm{H}_{2} \mathrm{O}_{2} 200 \mu \mathrm{M}$ during 1 hour on extracellular and intracellular (tachyzoites) 
parasites.

http:/ / www.biolsci.org/v07p0960s1.pdf

\section{Acknowledgements}

We thank M. Rincon, I. Curril and G. Ward for critical reading of the manuscript; K. Deitsch, C. Howitt A. Cassola, C. Frasch for technical assistance with RNA FISH; I. Curril for technical assistance with the TUNEL assay; K. Hager for providing Flag-TgRACK1 expressing strain; and A. Hakimi for TgAGO-HA encoding plasmid. This work was supported by the Vermont Genetics Network (VGN) through NIH grant 1 P20 RR16462 from the BRIN program of the NCRR; The American Heart Association AHA 0535047N; and the NIH P20 RR021905.

\section{Conflict of Interests}

The authors have declared that no conflict of interest exists.

\section{References}

1. Thomas MG, Loschi M, Desbats MA, and Boccaccio GL. RNA granules: the good, the bad and the ugly. Cell Signal 2010;23: 324-34

2. Anderson $\mathrm{P}$, and Kedersha N. RNA granules: post-transcriptional and epigenetic modulators of gene expression. Nat Rev Mol Cell Biol 2009; 10: 430-6

3. Balagopal V, and Parker R. Polysomes, P bodies and stress granules: states and fates of eukaryotic mRNAs. Curr Opin Cell Biol 2009; 21: 403-8

4. Cassola A, De Gaudenzi JG, and Frasch AC. Recruitment of mRNAs to cytoplasmic ribonucleoprotein granules in trypanosomes. Mol Microbiol 2007; 65: 655-70

5. Zhang M, Fennell C, Ranford-Cartwright L, Sakthivel R, Gueirard P, Meister S, Caspi A, Doerig C, Nussenzweig RS, Tuteja R, Sullivan WJJr, Roos DS, Fontoura BM, Menard R, Winzeler EA, and Nussenzweig V. The Plasmodium eukaryotic initiation factor-2alpha kinase IK2 controls the latency of sporozoites in the mosquito salivary glands. J Exp Med 2010;207: 1465-74

6. Kramer S, Queiroz R, Ellis L, Webb H, Hoheisel JD, Clayton C, and Carrington M. Heat shock causes a decrease in polysomes and the appearance of stress granules in trypanosomes independently of eIF2(alpha) phosphorylation at Thr169. J Cell Sci 2008; 121: 3002-14

7. Pomel S, Luk FC, and Beckers CJ. Host cell egress and invasion induce marked relocations of glycolytic enzymes in Toxoplasma gondii tachyzoites. PLoS Pathog 2008; 4: e1000188

8. Thompson J. In situ detection of RNA in blood- and mosquito-stage malaria parasites. Methods Mol Med 2002; 72: 225-33

9. Huynh MH, Rabenau KE, Harper JM, Beatty WL, Sibley LD, and Carruthers VB. Rapid invasion of host cells by Toxoplasma requires secretion of the MIC2-M2AP adhesive protein complex. EMBO J 2003; 22: 2082-90

10. Sheth U, and Parker R. Decapping and decay of messenger RNA occur in cytoplasmic processing bodies. Science 2003; 300: 805-8

11. Teixeira D, Sheth U, Valencia-Sanchez MA, Brengues M, and Parker R. Processing bodies require RNA for assembly and contain nontranslating mRNAs. RNA 2005; 11: 371-82

12. Braun L, Cannella D, Ortet $P$, Barakat $M$, Sautel CF, Kieffer $S$, Garin J, Bastien O, Voinnet $\mathrm{O}$, and Hakimi MA. A complex small RNA repertoire is generated by a plant/fungal-like ma- chinery and effected by a metazoan-like Argonaute in the single-cell human parasite Toxoplasma gondii. PLoS Pathog 2010;6(5):e1000920

13. Courchet J, Buchet-Poyau K, Potemski A, Bres A, Jariel-Encontre I, and Billaud M. Interaction with 14-3-3 adaptors regulates the sorting of hMex-3B RNA-binding protein to distinct classes of RNA granules. J Biol Chem 2008; 283: 32131-42

14. Jabri E. P-bodies take a RISC. Nat Struct Mol Biol 2005; 12: 564

15. Anderson P. A Place for RNAi. Dev Cell 2005; 9: 311-2

16. Kulkarni M, Ozgur S, and Stoecklin G. On track with P-bodies. Biochem Soc Trans 2010;38: 242-51

17. Caldas LA, de Souza W, and Attias M. Calcium ionophore-induced egress of Toxoplasma gondii shortly after host cell invasion. Vet Parasitol 2007; 147: 210-20

18. Caldas LA, de Souza W, and Attias M. Microscopic analysis of calcium ionophore activated egress of Toxoplasma gondii from the host cell. Vet Parasitol 2010;167: 8-18

19. Tomita T, Yamada T, Weiss LM, and Orlofsky A. Externally triggered egress is the major fate of Toxoplasma gondii during acute infection. J Immunol 2009; 183: 6667-80

20. Narasimhan J, Joyce BR, Naguleswaran A, Smith AT, Livingston MR, Dixon SE, Coppens I, Wek RC, and Sullivan WJJr. Translation regulation by eukaryotic initiation factor-2 kinases in the development of latent cysts in Toxoplasma gondii. J Biol Chem 2008; 283: 16591-601

21. Camps M, and Boothroyd JC. Toxoplasma gondii: selective killing of extracellular parasites by oxidation using pyrrolidine dithiocarbamate. Exp Parasitol 2001; 98: 206-14

22. Arimoto K, Fukuda H, Imajoh-Ohmi S, Saito H, and Takekawa M. Formation of stress granules inhibits apoptosis by suppressing stress-responsive MAPK pathways. Nat Cell Biol 2008; 10: $1324-32$

23. Lescault PJ, Thompson AB, Patil V, Lirussi D, Burton A, Margarit J, Bond J, and Matrajt M. Genomic Data Reveal Toxoplasma gondii Differentiation Mutants Are Also Impaired with Respect to Switching into a Novel Extracellular Tachyzoite State. PLoS One 2010;5: e14463

24. Moran JM, Smith SS, and Hager KM. Toxoplasma gondii possesses a receptor for activated C kinase ortholog. Biochem Biophys Res Commun 2007; 363: 680-6

25. Joyce BR, Queener SF, Wek RC, and Sullivan WJJr. Phosphorylation of eukaryotic initiation factor-2\{alpha\} promotes the extracellular survival of obligate intracellular parasite Toxoplasma gondii. Proc Natl Acad Sci U S A 2010; 107: 17200-5

26. Beckers CJ, Roos DS, Donald RG, Luft BJ, Schwab JC, Cao Y, and Joiner KA. Inhibition of cytoplasmic and organellar protein synthesis in Toxoplasma gondii. Implications for the target of macrolide antibiotics. J Clin Invest 1995; 95: 367-76

27. Schwab JC, Beckers CJ, Joiner K.A. The parasitophorous vacuole membrane surrounding intracellular Toxoplasma gondii functions as a molecular sieve. Proc Natl Acad Sci U S A. 1994; 91: 509-13

28. Bouchot A, Millot JM, Charpentier S, Bonhomme A, Villena I, Aubert D, and Pinon J.M. Membrane potential changes after infection of monocytes by Toxoplasma gondii. Int J Parasitol 2001; 31: 1114-20

29. Bouchot A, Zierold K, Bonhomme A, Kilian L, Belloni A, Balossier G, Pinon JM, and Bonhomme P. Tachyzoite calcium changes during cell invasion by Toxoplasma gondii. Parasitol Res 1999; 85: 809-18

30. Goldszmid RS, Coppens I, Lev A, Caspar P, Mellman I, and Sher A. Host ER-parasitophorous vacuole interaction provides a route of entry for antigen cross-presentation in Toxoplasma gondii-infected dendritic cells. J Exp Med 2009; 206: 399-410 